\title{
SMART WATER NETWORK MONITORING: A CASE STUDY AT UNIVERSITI TEKNOLOGI MALAYSIA
}

\author{
Nur Aida Azlin Abdul Aziz ${ }^{1}$, Tajul Ariffin Musa ${ }^{1,2}$, Ivin Amri Musliman ${ }^{1}$, Abdullah Hisam Omar ${ }^{1}$, Wan Anom Wan Aris ${ }^{1}$ \\ ${ }^{1}$ Geomatic Innovation Research Group, Faculty of Built Environment and Surveying, Universiti Teknologi Malaysia \\ ${ }^{2}$ Centre of Tropical Geoengineering (GEOTRPIK), Universiti Teknologi Malaysia
}

Commission 4, WG 7

KEY WORDS: IoT, water monitoring, GIS, real-time data, cloud computing.

\begin{abstract}
Water uses need to be measured, which is critical for evaluating water stress. The Industry 4.0 via the Internet of Things (IoT) and usage of water measurement sensor can provide real-time information on the water flow rate and water pressure, that is crucial for water monitoring and analysis. There is a need for online smart water monitoring that gives out more efficient and sustainable water uses at Universiti Teknologi Malaysia (UTM) campus. A prototype of an online smart water monitoring for UTM, which was developed based on the integration of IoT and Geographical Information System (GIS), consist of four layers; (1) physical layer; (2) network layer; (3) processing layer and, (4) application layer. The findings show that when the water flow increases, the water pressure decreases. When there is no water flow, the lowest value is 52.214 Psi, and the highest value is 60.916 Psi. The latest technology integrating the IoT-GIS for smart water monitoring has shown a very efficient way of providing real-time water parameters information, cost and time effective, and allowing for continuous water consumption analysis via the cloud computing service.
\end{abstract}

\section{INTRODUCTION}

Water is one of the world's most important resources. It has a major impact on human life and the sustainable development of society. As water is precious to everyone, its availability and quality are essential. Thus, water uses need to be measured, which is critical for evaluating water stress.

The industry 4.0 era has brought in different innovative technologies through other industrial sectors, such as manufacturing, water, energy, healthcare, and electronics. For example, contemporary Industry 4.0 innovations have been deemed ideal for the water sector, and innovative technologies are changing the water sector (Micheal Omotayo and Telukdarie, 2019). These new digital technologies, such as the Internet of Things (IoT), make it easier to collect and analyse data from smart water sensors and distribution networks, provide more flexibility, and efficient processes to produce higher-quality water network monitoring data at reduced costs (Verma et al., 2015). Trends show that utilities are increasingly taking advantage of Geographic Information System (GIS) to map and analyse geospatial data, including water, wastewater, and storm drain. Integration of GIS with IoT joins everything from sensors, geodatabase, analysis and applications, which are useful for water utilities and identifying problems like water leaks and pressure drops (Tate, 2021).

This paper will discuss a prototype development of an online smart water monitoring system at Universiti Teknologi Malaysia (UTM). This paper is organised as follows; Section 2 discusses the general methodology and data collection used in this study; the result and analysis of the prototype system are given in Section 3, and Section 4 provides the concluding remarks.

\section{THE METHODOLOGY}

A prototype of an online smart water monitoring for UTM, by interconnecting the GIS and IoT, consist of four layers; (1) physical layer; (2) network layer; (3) processing layer and (4) application layer.

\subsection{The Physical Layer}

The physical layer consists of any IoT system such as sensors and other data collection devices for sensing and gathering information on the physical parameters of the water network in the study area. It is the interface between the physical and digital domains and converts analogue to digital signals. Different sensory devices in this prototype development have been used, such as sensor node (model LRWPS-100), water flow sensor (model WL-LWGY-20), and water pressure sensor (model PCM380), to collect parameters like water flow, water pressure, water consumption, and location. Figure 1 shows the location of the sensors on the campus of UTM.

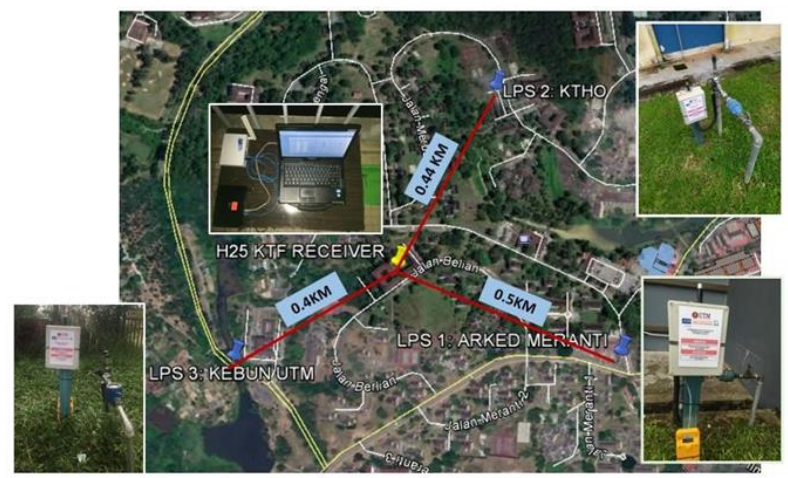

Figure 1. The location of sensors at UTM campus, Johor Bahru, Malaysia. 


\subsection{The Network Layer - Internet Gateway and Data Acquisition}

The IoT gateway on the network edge connects the local water sensor network and cloud services. It typically takes data from local devices and sends it directly to the cloud, where information is processed and delivered through web applications to users. LoRaWAN is a low-power, wide-area (LPWAN) network designed to wirelessly link devices to the Internet to achieve bi-directional communication between nodes and servers. The LoRa gateway can be represented as a bridge between a sensor and a server. Although the gateway has no data processing capability, it will gather all the data it collects from the nodes and then relays it to the server for processing. Data acquisition devices can be used to monitor water flow, water pressure, water consumption and location. The sensors generate a voltage or current signal at output depending on the physical phenomenon being measured.

\subsection{The Processing Layer - Data Processing and Data Analysis}

A centralised data system is important because it can help maintain efficiency by gathering and analysing water parameter data. Monitoring and supervision of water monitoring systems is the main purpose of this data centre system. Data is gathered and sent by the monitoring mechanism back to the data centre. The user interface shows water pressure and water flow rate, which can be tracked in real-time. At the same time, data analysis has been carried out, and the result can be used to estimate the water consumption pattern.

\subsection{The Application Layer}

In this application layer, the cloud computing system has been utilised in assembling the water parameters data and storage. Through this cloud system, it provides the opportunity to store and share the data anywhere and anytime. The cloud can accommodate a large amount of water parameter data, and it can be accessed for monitoring purposes via the website and the smartphone client. Figure 5 demonstrates cloud computing in smart water monitoring for UTM.

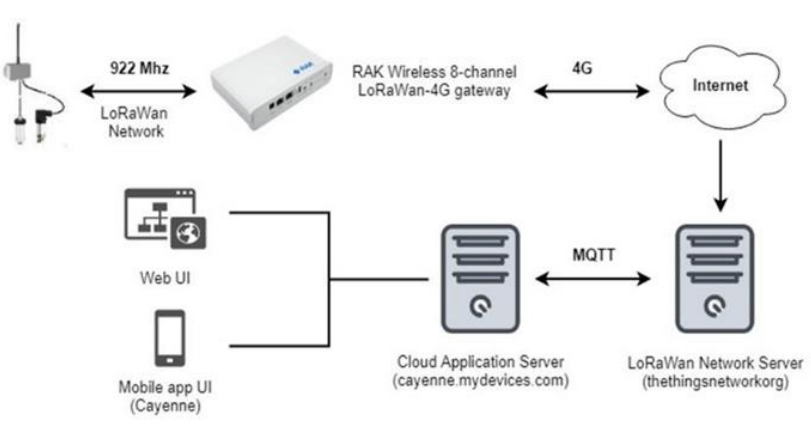

Figure 5. Cloud Computing in Smart Water Monitoring for UTM.

\subsubsection{Development of Web-based GIS for Sensor Node}

Database design is a process of creating database structure that fulfils the standards that have been defined based on user needs. The web-based information for sensor nodes can be set up to provide users with data and allow them to search for sensor node information based on their preferences. The database design process is divided into two phases: the conceptual design and logical design. In this study, there are two spatial entities which are land use and sensor node information. An EntityRelationship (ER) diagram signifies the real world for users to understand the relationship between entities, as shown in Figure 6. The logical design translates ER diagram to a relational database schema database (description of tables), including entity name, attribute name, description, and data type.

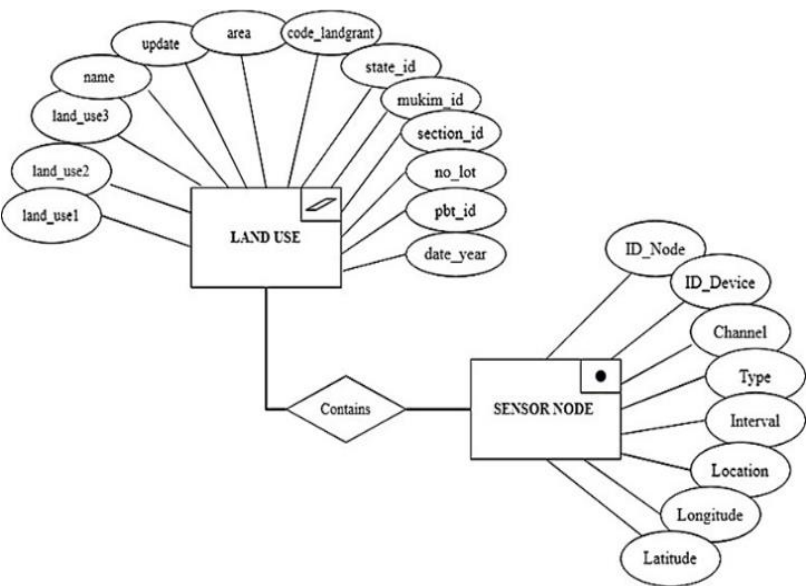

Figure 6. ER Diagram of Web-based GIS for Smart water monitoring.

\subsubsection{Application Interface Design}

The application interface is important to allow the website's contents to be correctly displayed. The website's content includes the Homepage (main page), Real-time Data, Data, Map, and Contact as shown in Figure 7. In general, web application was developed using Hypertext Markup Language (HTML), Cascading Stylesheets (CSS) and JavaScript (JS) technology stack.

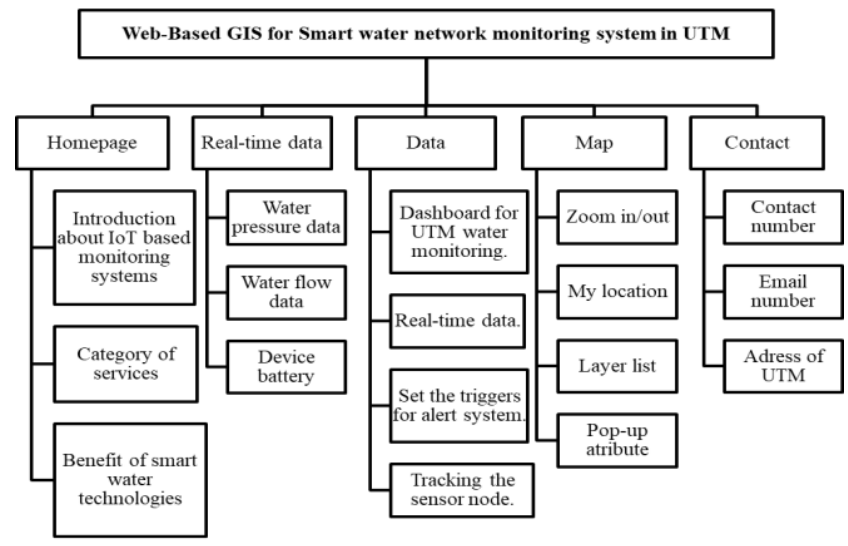

Figure 7. Application Interface Design for Web-based GIS for Smart Water Monitoring in UTM.

\subsubsection{Web Mapping Application and User Interface}

Web mapping effectively publishes GIS data on the Internet and makes it available to other users. QGIS2Web tool help to generate a web map of the same quality as a map created in a GIS. Fortunately, their available tools that make it simple to convert QGIS work to web maps. For example, the QGIS2Web plugin may produce a web map from your QGIS project using 
the OpenLayers or Leaflet libraries. Developing a web map in QGIS is the first stage in designing an online mapping application.

User Interface (UI) development by using HTML, CSS and JS is required to allow end-users to engage with the water monitoring system. End users can monitor and analyse trend information using elements such as real-time water flow, water pressure, location sensor node, and alert system.

\section{RESULT AND ANALYSIS}

\subsection{Application Interface}

The web-based GIS for smart water network monitoring in UTM contained five sections: Homepage, Real-Time Data, Data, Map, and Contact. The homepage is the first page that appeared when opening the website. Figure 7 shows the homepage with information on services.

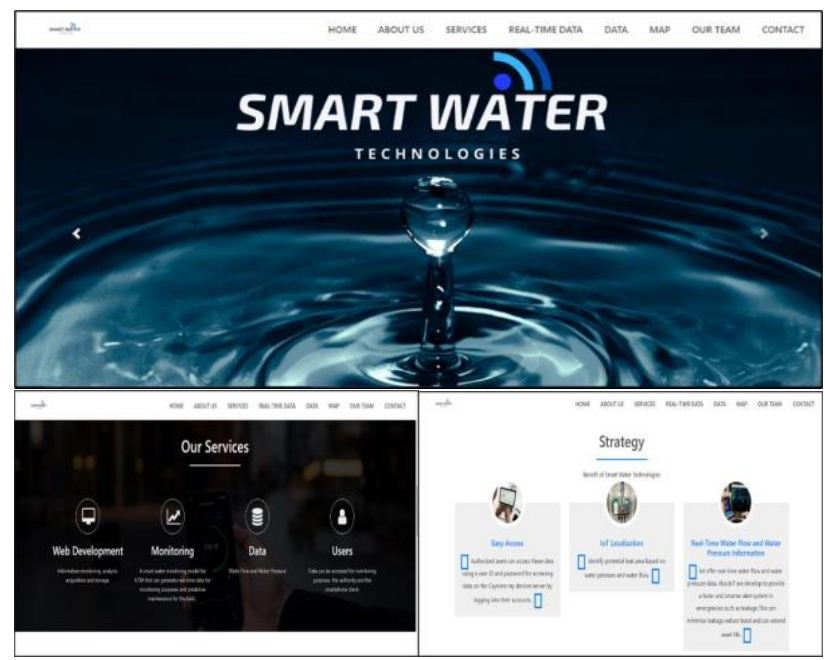

Figure 7. Homepage of the Website.

The second page displays real-time data for water pressure, water flow and device battery power. Again, users can access without logging in but can only see the value of water pressure and sensor, as shown in Figure 8.



Figure 8. Real-Time Data in interval 10 minutes.

On the third page of the website, authorised users can access these data using a user ID and password. Figure 9 shows the main page for authorised users to log in to their accounts. By logging into their account, users can use many features of smart water monitoring, such as tracking the sensor node, real-time data, and setting an alert system.



Figure 9. The Main Page for Authorized Users.

Figure 10, Figure 11, and Figure 12 show the features that authorised users can access. The map section was developed by using the QGIS2Web. The widgets on the map include zoom in, zoom out, and my location. Figure 13 and Figure 14 shows the map of the sensor node in UTM and attribute information, respectively.

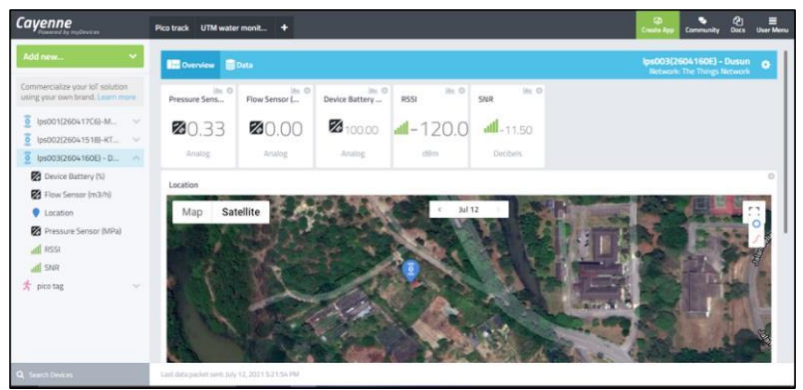

Figure 10. Dashboard for UTM water monitoring.

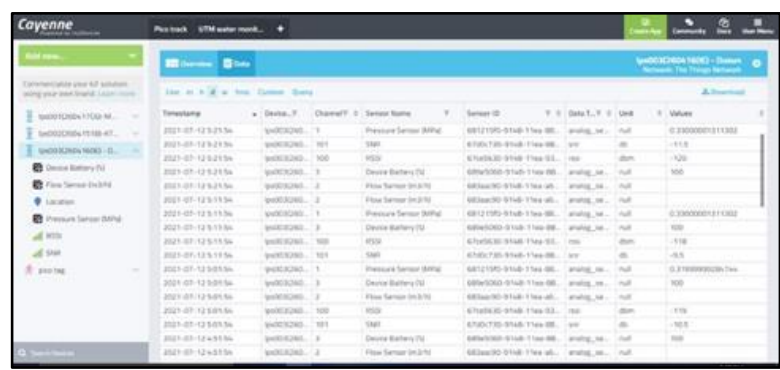

Figure 11. Real-Time Data

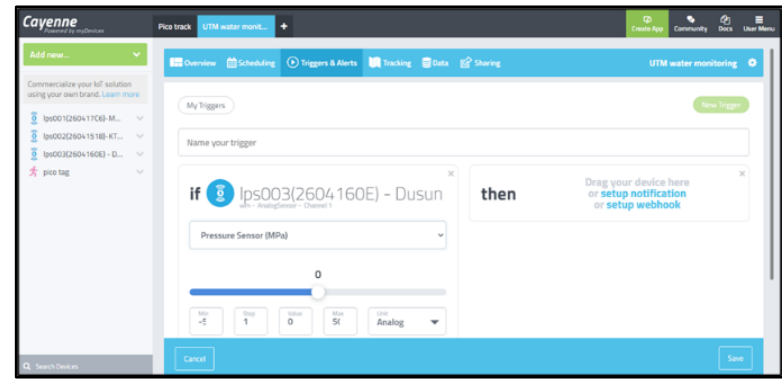

Figure 12. Authorised Users Can Set the Triggers for Alert System. 


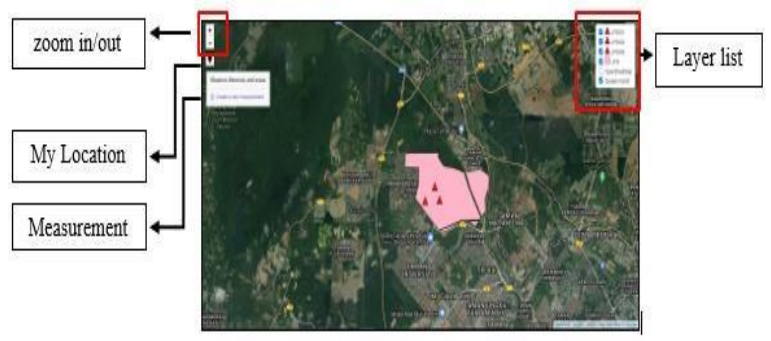

Figure 13. Overview of Maps of Web-Based GIS for Smart Water Network monitoring in UTM.
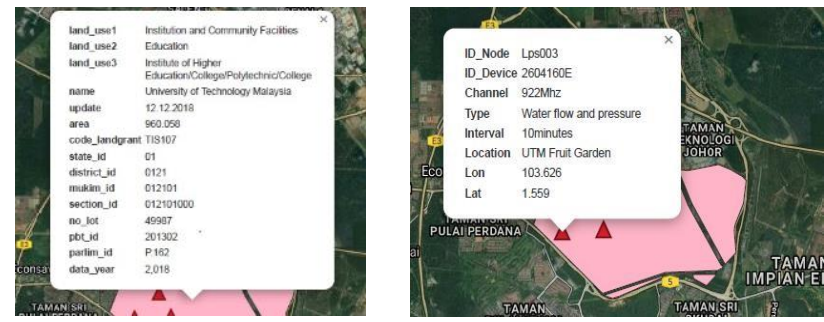

Figure 14. Pop-up attribute data for land use and sensor node information

\subsection{Water Flow and Water Pressure Analysis}

Based on three days of water pressure data, the lowest value when there is no water flow is $52.214 \mathrm{Psi}$, and the highest value is 60.916 Psi, as shown in Table 2. Based on data from three days of water flow rate and pressure, the minimum water flow is 0.167 litres, and the pressure is 55.114 Psi. The maximum water flow is 13.50 litres per minute, and the pressure is 11.63 Psi (Table 3).

\begin{tabular}{|c|c|}
\hline \multicolumn{2}{|c|}{ Water Pressure Value (Psi) } \\
\hline Minimum & 52.214 Psi \\
\hline Maximum & 60.916 Psi \\
\hline Average & 57.861 Psi \\
\hline
\end{tabular}

Table 1. Range of water pressure value if there is no water flow.

\begin{tabular}{|c|c|c|}
\hline $\begin{array}{c}\text { Range of } \\
\text { Water Flow }\end{array}$ & $\begin{array}{c}\text { Water Flow } \\
\text { (litres) }\end{array}$ & $\begin{array}{c}\text { Water Pressure } \\
\text { (Psi) }\end{array}$ \\
\hline Minimum & 0.167 litres & 55.114 Psi \\
\hline Maximum & 13.50 litres & 11.63 Psi \\
\hline
\end{tabular}

Table 2. Range of water pressure value if there have water flow.

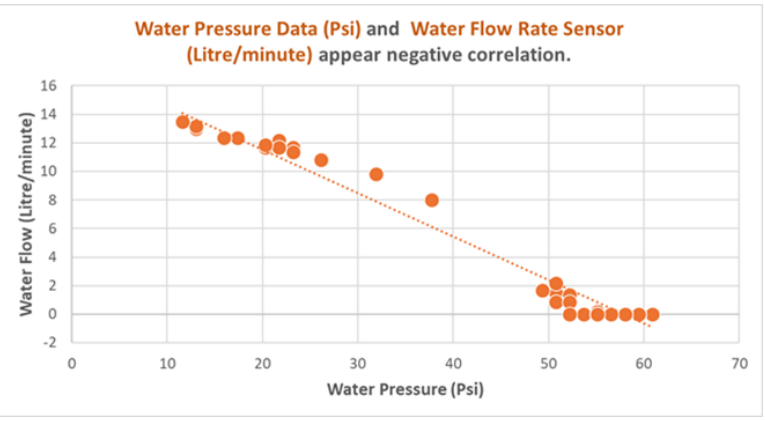

Figure 16. Data of water pressure and flow rate in three days.
Figure 16 shows that when the water flow increases, the water pressure decreases. This is the same concept as Bernoulli's Principle, which states that as the speed of a moving fluid increases, so the pressure within the fluid decreases.

The pipes' high-water pressure can shorten the pipe's lifespan, resulting in minor leaks and a pipe burst. Therefore, it is necessary to monitor the water pressure value to avoid pipe damage caused by high water pressure. Cayenne myDevices can be used to activate a trigger warning if the water pressure is too high. In this situation, the greater water pressure can be set to 80 psi so that smart water monitoring can assist users in extending the lifespan of water pipes while also preventing leakage.

\subsection{Water Consumption}

Water usage can be tracked in real-time mode and accessed via the Internet with smart water monitoring. The water consumption patterns show that there was less water usage, which can be associated with the COVID19 pandemic since fewer students stayed on the campus. Figure 17 shows the value flow rate (litres/minute) and the water consumption pattern, different every day.
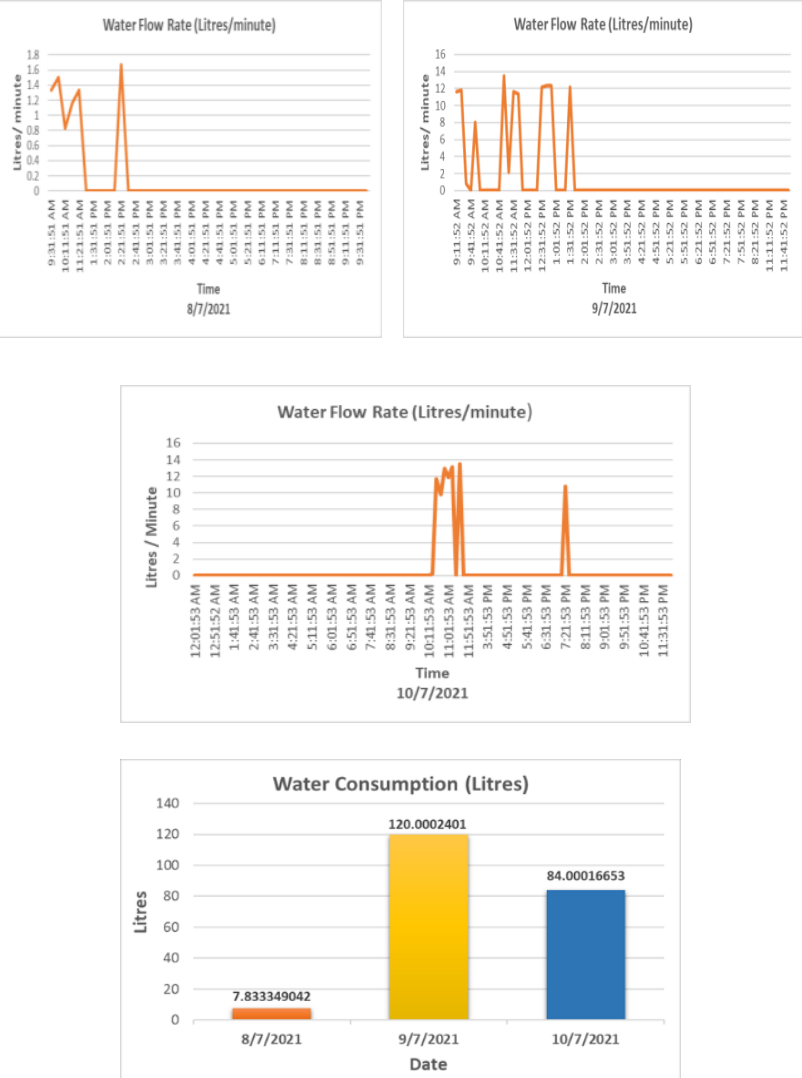

Figure 17. Data of water flow rate in three days.

\section{CONCLUDING REMARKS}

By integrating the IoT-GIS, the latest technology for smart water monitoring has shown a very efficient way of providing real-time water parameters information, cost and time effective, and allowing for continuous water consumption analysis via the cloud computing service. Nevertheless, the UTM smart water monitoring prototype should be further analysed with a long period of data collection. 


\section{ACKNOWLEDGEMENTS}

The author would like to thank Geomatic Innovation Research Group (UTM-GnG) \& GEOTROPIK for providing this study's data. The author also would like to channel an appreciation towards Universiti Teknologi Malaysia and Research University Grant (RUG) vot no. R.J13000.7352.4J341 for funding this study.

\section{REFERENCES}

Alshattnawi, S. K. (2017). Smart Water Distribution Management System Architecture Based on Internet of Things and Cloud Computing. 2017 International Conference on New Trends in Computing Sciences (ICTCS). https://doi.org/10.1109/ictcs.2017.31

Antzoulatos, G., Mourtzios, C., Stournara, P., Kouloglou, I.-O., Papadimitriou, N., Spyrou, D., Mentes, A., Nikolaidis, E., Karakostas, A., Kourtesis, D., Vrochidis, S., \& Kompatsiaris, I. (2020). Making urban water smart: the SMART-WATER solution. Water Science and Technology, 82(12), 2691-2710. https://doi.org/10.2166/wst.2020.391

Gonçalves, R., J. M. Soares, J., \& M. F. Lima, R. (2020). An IoT-Based Framework for Smart Water Supply Systems Management. Future Internet, 12(7), 114. https://doi.org/10.3390/fi12070114

Gupta, A. D., Pandey, P., Feijóo, A., Yaseen, Z. M., \& Bokde, N. D. (2020). Smart Water Technology for Efficient Water Resource Management: A Review. Energies, 13(23), 6268. https://doi.org/10.3390/en13236268

Gupta, K., Kulkarni, M., Magdum, M., Baldawa, Y., \& Patil, S. (2018). Smart Water Management in Housing Societies using IoT. 2018 Second International Conference on Inventive Communication and Computational Technologies (ICICCT). https://doi.org/10.1109/icicct.2018.8473262

Helena, R., Aonghus, M., López-Jiménez, P., \& Pérez-Sánchez Modesto, P.-S. (2019). Smart Water Management towards Future Water Sustainable Networks. Water, 12(1), 58. https://doi.org/10.3390/w12010058

Karwo, J., Wyczolkowski, R., Kaźmierczak, J., \& Paszkowski, W. (2016). Smart Water In Smart City: A Case Study. SGEM 16th International Scientific Conference on EARTH \& GEOSCIENCES, Albena, Bulgaria. Volume: 3/I.

Keen, L. (2019). Modelling of water distribution system with multiple water tanks. UTM repository.

Li, J., Yang, X., \& Sitzenfrei, R. (2020). Rethinking the Framework of Smart Water System: A Review. Water, 12(2), 412. https://doi.org/10.3390/w12020412

Micheal Omotayo, A., \& Telukdarie, A. (2019). Industry 4.0: Innovative Solutions For The Water Industry. Proceedings of the American Society for Engineering Management 2019, International Annual Conference E. Schott, E-H. Ng, H. Keathley, and C. Krejci eds, USA.

Tate, L. (2021). Utility Asset Management with IoT and GIS. Nobel Systems Inc. https://nobelsystemsblog.com/utility-asset-managementiot-gis/
Turcu, C., Turcu, C., \& Gaitan, V. (2018). An Internet of Things Oriented Approach for Water Utility Monitoring and Control. ArXiv.org. https://arxiv.org/abs/1811.12807

Verma, P., Kumar, A., Rathod, N., Jain, P., Mallikarjun, S., Subramanian, R., Amrutur, B., Kumar, M. S. M., \& Sundaresan, R. (2015). Towards an IoT based water management system for a campus. 2015 IEEE First International Smart Cities Conference (ISC2). https://doi.org/10.1109/isc2.2015.7366152 